\title{
North America, Central America and Caribbean (2018)
}

\author{
Kirsten Nakjavani Bookmiller*
}

\section{1 \\ Introduction}

Both slow and rapid onset natural hazard-generated events, many of them national record-breaking in impact, affected all North American, Central American and Caribbean countries leading up to and during 2018. Regardless of national income level, wildfires, hurricanes, cyclones, mass flooding, earthquakes, land/mud slides and volcanic eruptions considerably strained domestic emergency response capacities across the three regions, and in several cases triggered assistance requests from neighboring countries and the international humanitarian system. Significant food insecurity caused by persistent drought conditions in Central America's 'Dry Corridor' also intensified both internal displacement and outward migration rates.

Against this backdrop, regional and national efforts to strengthen disaster law frameworks addressing multi-hazard challenges continued apace in 2018. Central American and Caribbean governments pursued further legal measures aimed at reducing risk and strengthening resilience, building upon multifaceted efforts spanning over two decades. Meanwhile, Canada, Mexico and the United States (US) also took initial and unprecedented steps to address on-going legal and operational challenges related to cross-border assistance.

Despite significant exposure to a wide array of natural hazards, Canada, Mexico and the US have as a rule possessed sufficient domestic resources to individually respond to major national disasters, without the need for international assistance. Yet a rapid succession of crises in 2017 and 2018 has challenged

* PhD in Foreign Affairs (University of Virginia); Professor, Department of Government and Center for Disaster Research and Education, Millersville University (USA); Project Lead, North American Humanitarian Response Initiative, American Red Cross; Policy Volunteer, International Services, American Red Cross. The author beneficiated from the support provided by Sophie Tessyer Arrue, Coordinator for the Americas, Disaster Law and Legislative Advocacy (IFRC). 
this conventional wisdom. In September 2017, a devastating earthquake struck Mexico on the very anniversary of its 1985 catastrophic event, and after a previous earthquake episode and Hurricane Katia earlier in the month. Recordbreaking wildfire seasons raged in Canada in both 2017 and 2018. For the US, 2017 brought California wildfires combined with Hurricanes Harvey, Irma and Maria striking within one month of each other (and during an already historic Atlantic hurricane season). The chain of disasters so fully outstripped the US Federal Emergency Management Agency's ability to effectively respond ${ }^{1}$ that the government was forced to make an unprecedented official request for international assistance for the first time in its history. ${ }^{2}$ A year later the US was further beset by Hurricanes Florence and Michael and an additional round of devastating California wildfire outbreaks.

On 14-15 March 2018, the American Red Cross, in partnership with the Canadian Red Cross and Mexican Red Cross, convened the North American Humanitarian Response Summit (NAHRS) in Washington, DC. The first ever regional diplomatic engagement effort of its kind, comprising of the three National Societies, counterpart government officials as well as other humanitarian sector representatives, NAHRS was dedicated to strengthening North American post-disaster mutual assistance. Despite a high level of mutual aid activity, a project-related legal scan concluded that a complex array of federal and state/provincial laws and regulatory instruments within all three countries significantly undermined its overall efficiency. ${ }^{3}$

The NAHRS process in total encompassed five meetings held from September 2017-March 2018, including a convening meeting (also in Washington, DC), three preparatory sessions held in Mexico, the US and Canada and the culminating summit. ${ }^{4}$ The summit generated five aggregate 'key action points' or strategic recommendations. Three of them reflected long-standing

1 Federal Emergency Management Agency, '2017 Hurricane Season FEMA After-Action Report, July 12, 2018', available at <https://www.fema.gov/media-library-data/1533643262195-6d13983 39449ca85942538a1249d2ae9/2017FEMAHurricaneAARv20180730.pdf> last accessed (as any subsequent URL) on 27 June 2019.

2 Andrew Slaten, 'The International Assistance System (IAS): Atypical Resourcing and Management of International Assistance During a Domestic US Disaster', Presentation at the Joint Meeting of International Disaster Law Experts-North American Humanitarian Response Initiative Working Group on Teams, Personnel and their Equipment, Millersville University (21 February 2019).

3 Kirsten Nakjavani Bookmiller, 'North American Humanitarian Response Summit Project Multinational Legal and Policy Preparedness Scan' (2017) <https://media.ifrc.org/ifrc/wpcontent/uploads/sites/5/2018/02/Policy-Scan.pdf>.

4 Final reports for all NAHRS-related meetings are available at $<$ https://www.preparecenter .org/content/north-american-humanitarian-response-summit-nahrs $>$. 
International Disaster Response Law concerns, including the need for: (1) prequalification/credential recognition of international emergency medical teams and other specialized response personnel; (2) a waiver process for incoming humanitarian responders; and (3) pre-certification of incoming supplies and equipment. ${ }^{5}$

In June 2018, the three North American Red Cross National Societies launched a successor process, titled the North American Humanitarian Response Initiative (NAHRI). NAHRI further progressed NAHRS' work by convening three Thematic Working Groups (TWGs) in the areas of Specialized Teams, Personnel and Their Equipment, Supplies and Accountability to Underserved Populations. Through the respective TWG s, Red Cross and government officials from Canada, Mexico and the US continued high-level consultations postNAHRS as well as supported further academic research related to all three areas of concern. Pending further funding, NAHRI was scheduled to conclude in March 2019.

\section{3}

\section{Central America}

Central America is considered to be one of the world's top disaster risk 'hot spots.' ${ }^{6}$ Its geographic positioning between the Pacific Ocean and Caribbean Sea, upon a highly volatile seismic zone and within an area of extreme climate variability, exposes the region to significant hydrometeorological and geophysical hazards. This acute exposure, combined with endemic economic, political and societal fragility in many cases, means that both high and low frequency disaster events will often have a profound humanitarian impact. ${ }^{7}$

The Central American Integration System (SICA) ${ }^{8}$ the region's principal intergovernmental body since 1991, has dedicated significant legal and policy attention to this domain. Its member States have identified the prevention and

5 Global Emergency Group, 'North American Humanitarian Response Summit (NAHRs) Project Summit Meeting Report March 14-15, 2018', <https://www.preparecenter.org/sites/ default/files/nahrs_summit_meeting_final_report_-_may_15_2018.pdf $>$.

6 Bündnis Entwicklung Hilft and Ruhr University Bochum-Institute for International Law of Peace and Armed Conflict, 'World Risk Report 2018', available at <https://weltrisikobericht .de/wp-content/uploads/2019/03/190318_WRR_2018_EN_RZonline_1.pdf>.

7 UNISDR y CE PREDENAC, 'Informe Regional del Estado delaVulnerabilidad y Riesgos de Desastres en Centroamérica', available at <https://issuu.com/cepredenac/docs/informe-regional -centromericano-rar>.

8 Sistema de la Integración Centroamericana; the Spanish acronym 'SICA' is also used in English. 
mitigation of natural disasters and climate change impacts as one of the five main pillars of contemporary Central American integration. ${ }^{9}$ Spurred by the shared trauma of 1998 Hurricane Mitch, SICA has facilitated the development of an impressive subregional legal framework around prevention, preparedness and cross-border response over the past two decades, often progressed through its biannual summit meetings. ${ }^{10}$ Key guiding instruments in effect partly or exclusively focused upon humanitarian assistance-related matters include: the 2006 Central America-4 (CA-4) Border Control Agreement; the 2008 Central American Customs Code and Regulation (CAUCA/RECAUCA); ${ }^{11}$ the 2014 Central American Protocol for the Shipment, Transit and Reception of Humanitarian Assistance (2014 Protocol):12 the 2014 Regional Mechanism for Mutual Assistance in Disasters (MecReg-sICA); ${ }^{13}$ the 2017 Central American Policy on Comprehensive Disaster Risk Management in Central America, 2017-2030 (PCGIR) ${ }^{14}$ and the 2017 Reference Procedures on the Facilitation of the Shipment, Transit and Receipt by Land of International Disaster Relief within the SICA Region (2017 Reference Procedures). ${ }^{15}$

SICA's primary institutional mechanism for sector related activities is its Coordination Center for the Prevention of Disasters in Central America and the Dominican Republic (CEPREDENAC), a specialized secretariat dedicated to disaster management coordination. ${ }^{16}$ Throughout its existence, CEPREDENAC

9 SICA, 'Declaración Conjunta y Plan de Acción - Cumbre Extraordinaria de Jefes de Estado y de Gobierno de Países del sica para el Relanzamiento del Proceso de la Integración Centroamericana' (20 July 2010) art. 4.

$10 \quad$ SICA, 'Cronología de Reuniones - La Reunión de Presidentes', available at <https://www .sica.int $/$ consulta/reuniones.aspx?identstyle $=401$ \&ident $=1 \&$ \&idm $=1$ \&idmstyle $=2>$.

11 Council of Ministers of Economic Integration (COMIECO), CAUCA, Resolution 223-2008 (COMIECO-XliX); COMIECO, RECAUCA, Resolution 224-2008 (COMIECO-XLIX). Both resolutions came into effect on 25 August 2008.

12 SICA, 'Protocolo Centroamericano de Envío, Tránsito y Recepción de Asistencia Humanitaria y Técnica Internacional en Situaciones de Desastres/Emergencias' (2014).

13 SICA, 'El Mecanismo Regional de Ayuda Mutua ante Desastres del Sistema de la Integración Centroamericana' (2014). The first version of the MecReg-SICA was issued in 2001 and has been updated continually.

14 Sica and cepredenac, 'Política Centroamericana de Gestión Integral de Riesgo de Desastres' (2017). The first version was approved in 2010 and set the stage for the MecReg's development. The 2017 document updates and harmonizes its content in line with the Sendai Framework.

15 SICA, 'Procedimiento de Referencia Sobre la Facilitación del Envío, Tránsito y Recepción por tierra de Ayuda Internacional para Desastres dentro de la Región del sicA' (2017).

16 CEPREDENAC was formed prior to SICA as an expert body in 1987. In 1993 it was integrated into SICA, becoming a specialized secretariat. Its legal authority is derived from a constitutive agreement that entered into force in 2009 . 
has been a major facilitator of regional intergovernmental arrangements and promotes national and regional observance of global frameworks such as the Sendai Framework for Disaster Risk Reduction 2015-2030 (Sendai). ${ }^{17}$ On the national level, many member States have designated special units within their respective Foreign Affairs ministries and Emergency Operations Centers. The latter are known as Humanitarian Assistance Coordination Centers $(\mathrm{CCAH}(\mathrm{I}) / \mathrm{CATAI})^{18}$ and facilitate inter-institutional coordination of requests for and reception of international assistance. In each case, national manuals and guidelines have been developed and revised reflecting new regional level legal and policy mandates.

Within that context, in 2018 both Costa Rica and Honduras approved revisions of their respective national CCAH/CATAI Guidelines, incorporating the 2014 Protocol and 2017 Reference Procedure provisions after a multi-year process. Another global legal instrument, the International Disaster Response Law Guidelines (IDRL Guidelines), promulgated by the International Federation of the Red Cross and Red Crescent Societies (IFRC), informed the development of draft national legislation in Belize and Panama. In Guatemala, the April 2018 Allied Humanitarian Forces Exercise (FAHUM), simulated the activation of that country's CCAH, evaluating both its Declaration of Public Calamity Decree and its CСAH Manual in operation. Based on both FAHUM's outcome and the government's actual response to the eruption of the Fuego Volcano shortly thereafter, Guatemala has pledged to consider the IDRL Guidelines in its reassessment of the country's National Strategy on Comprehensive Disaster Risk Management. Related to specific procedures, the Costa Rican Red Cross secured a tax exemption for incoming humanitarian assistance goods outside of officially declared national emergencies. Costa Rica is also considering a new national law on Emergencies and Risk Prevention. ${ }^{19}$

On the disaster risk reduction front, SICA and CEPREDENAC continue to implement the Regional Plan for Disaster Risk Reduction, 2014-2019 (PRRD). The PRRD's main objectives are to contribute to: (1) reducing regional asymmetries regarding comprehensive disaster risk management in tandem with national focal points; (2) current national level progress in the sector by jointly promoting exchange, development, demonstrated consolidated action and

17 For a list of current projects, refer to <http://www.cepredenac.org/index.php/ proyectos>.

18 Depending on the country, the national center acronym in Spanish may be CCAH, CCAHI or CATAI.

19 IFRC, 'Disaster Law Programme Annual Report 2018', available at <https://media.ifrc.org/ ifrc/wp-content/uploads/sites/5/2019/05/DLP-2018-Annual-Report_Final.pdf>. 
good regional practices; and (3) common and integrated regional development by coordinating and articulating comprehensive disaster risk management within Central American regional development policies and strategies. ${ }^{20} \mathrm{On}$ 16-17 August 2018, CEPREDENAC organized a regional consultation workshop in Panama in order for national and regional stakeholders to provide feedback on a first draft of the 2019-2023 PRRD. The newest edition will include indicators, regional strategies and monitoring mechanisms with the goal of further aligning the PRRD with the PCGIR and Sendai. ${ }^{21}$ CEPREDENAC member States' national disaster management and statistical reporting agencies also participated in a technical training workshop addressing Sendai-related data collection and indicator monitoring on 19 November 2018 in Panama. ${ }^{22}$ On the intergovernmental level, following the $5^{2 n d}$ regular meeting of sicA's Heads of State and Governments on 14 December 2018, the group issued an official statement as part of the Declaration of Belize, urging continued high level attention to the mitigation of the harmful effects of climate change for its most vulnerable members. ${ }^{23}$

Notably, 2018 also marked the 2oth anniversary of Hurricane Mitch striking the region. It is a SICA and CEPREDENAC customary practice to utilize Mitch's commemoration as an important touchstone to measure progress across the sector. On 31 October 2018, CEPREDENAC convened a meeting of a broad spectrum of national, regional and international stakeholders in Honduras to assess progress to date regarding risk reduction measures in the area. The participants cited the significant headway made regarding not only the development of each member-States' disaster management capacity, but also accompanying legislative frameworks that were increasingly harmonized with global level instruments, including Sendai. Still, attendees noted the significant work remaining in light of the region's substantial vulnerabilities. ${ }^{24}$

20 Sica and cepredenac, 'Plan Regional de Reducción de Riesgo de Desastres PrRd (2014-2019)', 13 .

21 'Second Regional Consultation Workshop for the Definition of Regional Indicators of the Disaster Risk Reduction Plan in Central America' (16-17 August 2018), available at <http:// www.cepredenac.org/index.php/blog/notao101>.

22 Undrr, 'Países Miembros de cepredenac se Capacitan Sobre el Marco de Sendai para la Reducción del Riesgo del Desastre 2015-2030' (19 November 2018), available at $<">$ https://eird.org/americas/noticias/paises-miembros-de-cepredenac-se-capacitan-sobre-el-marco-de-sendai-para-la-reduccion-del-riesgo-del-desastre-2015-203o.html\#. XPaHyohKg2y>.

23 LII Reunión Ordinaria de Jefes de Estado y de Gobierno de los Países Miembros del Sistema de la Integración Centroamericana, 'Declaración de Belize' (14 December 2018).

24 Cepredenac, 'Regional Meeting: Progress, Challenges and Perspectives of the Central American Region and the Dominican Republic, 20 Years of Hurricane Mitch' (News Blog, ${ }_{31}$ October 2018) available at <http://www.cepredenac.org/index.php/blog/notao113>. 
The Greater Caribbean region possesses extraordinary political, economic and cultural diversity, and consists not only of thirteen small island States, but also several Central and South American coastal States, others that culturally selfidentify as Caribbean and numerous non-sovereign territories that frequently participate in many 'local' intergovernmental fora. It is also home to several subregional organizations with a patchwork of overlapping and discrete national memberships, including the Caribbean Community (САRICOM), the Association of Caribbean States (ACS), the Organization of Eastern Caribbean States (oECS) and to a lesser extent, SICA (discussed previously). All of these entities focus on natural disaster threats either as a formal part of their legal mandate or through institutional attention and on-going activities. This attention is not surprising given that ' $[0]$ ver the past 20 years, natural disasters have directly affected 1.2 million people in the Caribbean on average, and not a single year has passed in which disasters in the Caribbean have not claimed lives', according to a 2018 World Bank report. ${ }^{25}$ While in 2017 the unprecedented devastation caused by the successive landfalls throughout the region of Hurricanes Harvey, Irma and Maria drew international attention, the Caribbean is consistently exposed to numerous hydro-meteorological and geophysical hazards. When further factoring in a complex mix of climate change impacts (especially sea level rise), extreme seasonal climate variability, historically weak land management practices, significant socio-economic fragility and the constrained capacities of small developing economies in many cases, the Caribbean ranks among the most globally vulnerable related to disaster-related damage, frequency and affected population levels. ${ }^{26}$

At the sector's regional forefront is the Caribbean Disaster Emergency Management Agency (CDEMA), created by CARICOM in 1991. 'Climate Adaptation and Mitigation and Disaster Mitigation and Management' is one of CARICOM's ten 'high priority areas' as outlined in its $2015^{-2019}$ Strategic Plan. ${ }^{27}$ With 18 members, CDEMA is dedicated to 'fully take up its role as facilitator, driver, coordinator and motivating force for the promotion and engineering of

25 World Bank, 'Disaster Risk Management in The Caribbean: The World Bank's Approaches and Instruments for Recovery and Resilience' (2018), available at <https://www.gfdrr.org/ sites/default/files/publication/WBG\%2oCaribbean\%2oDRM\%2oEngagement_web.pdf>.

26 Sònia Muñoz and İnci Ötker, 'Building Resilience to Natural Disasters in the Caribbean Requires Greater Preparedness' (IMF Country Focus, 10 December 2018), available at $<$ https://www.imf.org/en/News/Articles/2018/12/o7/NA120718-Building-Resilience-to -Natural-Disasters-in-Caribbean-Requires-Greater-Preparedness $>$. com' (3 July 2014), iv. 
Comprehensive Disaster Management (CDM) in all Participating States'. ${ }^{28}$ It actively promotes and monitors the development, adoption and implementation of regional cooperative frameworks and sector-related national policies and legislation. Both the 1991 agreement which founded CDEMA's predecessor, the Caribbean Disaster and Emergency Response Agency (CDERA) ${ }^{29}$ and CDEMA's 2008 constitutive document strongly inform its work. ${ }^{30}$ Since 2001, a series of CDM strategies and frameworks have also guided the agency's efforts. The current Regional Comprehensive Disaster Management Strategy and Programming Framework, 2014-2024 (2014-2024 Framework), emphasizes regionwide resilience building strategies that incorporate climate change, gender, communications and environmental sustainability-sensitive planning. ${ }^{31} \mathrm{CDE}-$ MA updated the 2014-2024 Framework at the global level in 2017 to more effectively align with Sendai by adding 6 additional indicators. It views the Framework as an instrumental platform to implement Sendai's objectives. ${ }^{32}$ Along with Sendai, CDEMA also embraces the agendas set forth by both the Climate and Sustainable Development regimes. ${ }^{33}$

The agency additionally supports national-level disaster law capacity building, having issued an impressive array of model legislative and policy instruments, including the 2010 Model Comprehensive Disaster Management Legislation and Regulations, ${ }^{34}$ the 2012 Comprehensive Disaster Management: A Model National Comprehensive Disaster Management Policy and accompanying Adaptation Guide and a further 2013 Model Comprehensive Disaster Management Legislation and Regulations template. ${ }^{35}$

28 CDEMA, 'About Us', available at <https://www.cdema.org/about-us\#what-is-cdema-s -mandate>.

29 CARICOM, 'Agreement Establishing The Caribbean Disaster Emergency Response Agency' (26 February 1991).

3o CARICOM, 'Agreement Establishing The Caribbean Disaster Management Agency' (2009).

31 CDEma, 'Regional Comprehensive Disaster Management (CDM) Strategy and Programming Framework 2014-2024' (2014).

32 CDEma, 'Statement of Mr. Ronald Jackson, Executive Director, Caribbean Disaster Emergency Management Agency at the Global Platform for Disaster Risk Reduction, Cancun, Mexico 22-26 May 2017', available at <https://www.cdema.org/38-speeches/speeches/ 1673-statement-of-mr-ronald-jackson-executive-director-caribbean-disaster-emergency -management-agency-at-the-global-platform-for-disaster-risk-reduction-cancun-mexico -22-26-may-2017>.

33 CDEMA, 'CDM', available at <">https://www.cdema.org/cdm\#cdm-strategy>.

34 This instrument replaced an inaugural 1996 version titled 'Disaster Preparedness Model Legislation'.

35 For a comprehensive list of guidance documents utilized by CDEMA, refer to <https:// www.cdema.org/virtual-library/cdema-cu-partners-products-documents/ guidance-tools >. 
One of CDEMA's oldest operational mandates is to coordinate assistance to disaster impacted States. Its Regional Response Mechanism (RRM) is a multitiered, humanitarian response surge arrangement, involving national, regional and international aid providers, guided by the Regional Disaster Response Support Doctrine. The RRM has generated numerous standard operating procedures, guidelines, protocols and memoranda of understandings under its auspices and recognizes International Humanitarian Law (IHL) as a major guiding reference point. ${ }^{36}$

Following the profound devastation caused by the 2017 hurricane season (within which a three-week period alone $50 \%$ of CDEMA States were impacted), ${ }^{37}$ CARICOM's leadership redoubled its commitment to developing resilience-based strategies in 2018. After the 29th Inter-Sessional Meeting of the Conference of Heads of State held in Haiti on 26-27 February 2018 urged renewed attention to the sector, a series on multi-level meetings were held throughout $2018^{38}$ which ultimately led to a new 'Caribbean Pathway for Resilience'. The new strategy is a further refinement of the 2014-2024 Framework. Termed 'Enhanced Pathways', the five pillars include: (1) Social Protection for the Marginal and Most Vulnerable; (2) Safeguarding Infrastructure; (3) Enhancing Economic Opportunity; (4) Environmental Protection; and (5) Operational Readiness. ${ }^{39}$ They are designed to make CARICOM the world's first 'climate resilient region', a major strategic objective of the organization's chairman and President of Haiti Jovenel Moïse, who launched his term in January $2018 .{ }^{40}$

CDEMA also reiterated its commitment to implement the Sendai Framework at the Sixth Regional Platform for Disaster Risk Reduction held in Cartagena, Columbia on 20-22 June $2018 .{ }^{41}$ One major CDEMA path to implementing

36 CDEMA, 'The Regional Response Mechanism: RRM' (2016), available at <https://www .cdema.org/RRM_Booklet_Final_PDF_version.pdf>.

37 CDEMA, 'Building a Caribbean Pathway for Disaster Resilience in the Caribbean Community' (2018), available at <https://www.cdema.org/Building_A_Caribbean_Pathway_For _Disaster_Resilience_In_The_Caribbean_Community_(CARICOM).pdf >.

38 The issue also received high level attention at the 39th Regular Meeting of the Conference of Heads of Government of the Caribbean Community on 4-6 July 2018 in Jamaica.

39 CDEMA, 'Building a Caribbean Pathway for Disaster Resilience in the Caribbean Community' (2018), available at <https://www.cdema.org/Building_A_Caribbean_Pathway_For _Disaster_Resilience_In_The_Caribbean_Community_(CARICOM).pdf >.

40 Dana Niland, 'Caribbean Looks to Become World's First Climate-Resilient Region' Caribbean Journal, 4 January 2018, available at <https://www.caribjournal.com/2018/o1/o4/ caribbean-looks-become-worlds-first-climate-resilient-region>.

41 CDema, 'CDema's Participation in the Sixth Regional Platform for Disaster Risk Reduction 2018, Cartagena, Columbia' (Press Release, 28 June 2018), available at $<$ https:// 
the Sendai agenda centers around strengthening regional Early Warning Systems (EWs). Efforts include the issuance of redesigned Ews guidelines in partnership with the IFRC and the UN Development Program via a new August 2018 toolkit. ${ }^{42}$ It also launched a new regional EWs strategy development process in conjunction with the World Bank, World Meteorological Organization and other partners during a 22 November 2018 meeting in Barbados. Its principal aims include furthering national capacity building along with adopting a more people-centered approach. ${ }^{43}$

Beyond CDEMA, CARICOM's Caribbean Regional Fisheries Mechanism (CRFM) approved a fast-tracked Protocol on Climate Change Adaptation and Disaster Risk Management in Fisheries and Aquaculture during the CRFM's Ministerial Council meeting in Barbados on 11 October 2018. ${ }^{44}$ The new regional protocol is intended to integrate climate change adaptation and disaster risk management perspectives into the Caribbean Community Common Fisheries Policy and emerges out of a new technical agreement between the CRFM and the Food and Agricultural Organization. ${ }^{45}$

In other regional developments, the Special Committee for Disaster Risk Reduction of the Association of Caribbean States, for which natural hazards is a primary area of organization concern ${ }^{46}$ met to discuss progress related to its Havana Plan of Action $2016-2018^{47}$ and launched a new drafting process of the

www.cdema.org/news-centre/press-releases/1803-cdema-s-participation-in-the-sixth -regional-platform-for-disaster-risk-reduction-2018-cartagena-columbia >.

42 UNDP Latin America and Caribbean, 'CDEMA, IFRC and UNDP launched Early Warning Toolkit' (Press Center, 28 August 2018), available at <http://www.latinamerica.undp.org/ content/rblac/en/home/presscenter/articles/2018/early-warning-system-toolkit-re -designed.html>.

43 cdema, 'Building Towards People-centric Early Warning systems in the Caribbean' (Press Release, 22 November 2018), available at <https://www.cdema.org/news-centre/ press-releases/1853-building-towards-people-centric-early-warning-systems-in-the -caribbean>.

44 'Fisheries Ministers Approve Climate Change Protocol for CRFM Member States' (Caricom Today, 16 October 2018), available at $<$ https://today.caricom.org/2018/10/15/fisheriesministers-approve-climate-change-protocol-for-crfm-member-states/>.

45 Association of Eastern Caribbean States, 'CRFM Fast Tracks Protocol for Climate Change and Disaster Risk Management in Fisheries and Aquaculture' (Media Center, 24 February 2018), available at <https://pressroom.oecs.org/crfm-fast-tracks-protocol-forclimate-change-and-disaster-risk-management-in-fisheries-and-aquaculture $>$.

46 Association of Caribbean States, 'About the Acs', available at <http://www.acs-aec.org/ index.php?q=about-the-acs $>$.

47 The ACs Meeting of Heads of State and/or Government, Havana, Cuba: June 4, 2016 Plan of Action for 2016-2018. 
2019-2021 Plan in Trinidad and Tobago on 11 June 2018.48 On the national level, Dominica (whose total damages and losses from the 2017 hurricane season exceeded $224 \%$ of its GDP $)^{49}$ drafted a new Disaster Risk Management Law in 2018.50

\section{$5 \quad$ Conclusion}

Despite the remarkable political and socio-economic diversity present across North America, Central America and the Caribbean, the regions all share a serious threat to the security and well-being of their respective communities. Each is highly prone to destructive natural hazard-driven events and will be increasingly so due to intensifying climate change impacts. In 2018, North America took the initial steps in identifying barriers to efficient and effective cross-border mutual assistance. The impediments are inherently legal in nature, but so are the solutions. For examples of vibrant region-based disaster law practice, North America need look no further than to those provided by SICA and CARICOM. Both entities have contributed to IDL's development since its earliest emergence as a recognized field, and in 2018 each continued to carve a legal path that was both context appropriate and yet largely in sync with global developments.

48 Association of Caribbean States, 'xxvi Meeting of the Special Committee for Disaster Risk Reduction' (Press Center, 2018), available at <http://www.acs-aec.org/index .php?q=press-center/releases/2018/xxvi-meeting-of-the-special-committee-for-disaster -risk-reduction $>$.

49 World Bank, 'A 360 Degree Look at Dominica Post Hurricane Maria' (28 November 2018), available at <https://www.worldbank.org/en/news/feature/2017/11/28/a-36o-degree-look -at-dominica-post-hurricane-maria>.

IFRC, Disaster Law Programme Annual Report 2018 (n. 19). 